\title{
Infancia callejera: aproximación crítica a sus investigaciones y perspectivas desde la teoría socialı
}

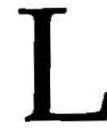

os niños de la calle, es decir la población de ambos sexos, menor de 17 años que viven y duermen varios dias seguidos en la calle sin ser acompañados por adultos2, es considerado uno de los problemas más graves de los países en desarrollo, especialmente en América Latina, donde, según datos estimados, se concentra la mitad de los niños de la calle existentes a nivel mundial.

La investigación sobre la infancia callejera se encuentra todavía en su fase inicial. Aisladamente se encuentran algunos enfoques que, partiendo de aspectos descriptivos, logran llegar a un cierto nivel de abstracción. Las pocas investigaciones que existen se refieren fundamentalmente a los niños callejeros de Colombia. Por esta razón, la discusión de los enfoques que reseñamos a continuación, se circunscribe, salvo escasas excepciones, a la discusión científica de la infancia callejera colombiana. No obstante, como se demostrará en la discusión que sigue la formulación de los enunciados es casi siempre tan genérica que éstos encuentran aplicación para todo el área cultural de Latinoamérica, y aún más allá.

\section{Enfoques respecto al entorno del individuo}

En los enfoques relativos al entorno del individuo se destacan aquéllos factores que se encuentran en la constitución individual de cada niño. El punto de vista está orientado primariamente a aquéllos niños que han roto todo contacto con la familia y viven en la calle en grupos con niños iguales a ellos. ${ }^{3}$ Los seguidores de estos enfoques también coinciden en su afirmación de que los niños callejeros se caracterizan por un estilo de vida típico, el cual se manifiesta, por ejemplo, a tráves de dormir en la acera, robar, mendigar, jugar, hacer travesuras, etc. Pero la justificación teórica de estas conductas, así como de otras, se basa en cada uno de los 
enfoques en diferentes formas de apreciación, que se expondrán a continuación.

\subsection{El enfoque psicopatológico}

El enfoque psicopatológico constata hondas perturbaciones emocionales del niño de la calle. Varios psiquiatras colombianos han desarrollado este enfoque, que se basa en investigaciones sobre la vagancia infantil de Bogotá.

Ballesteros Rotter presenta detalladamente los resultados obtenidos del trabajo en una clinica psiquiátrica. ${ }^{4}$ En las historias clínicas de 151 niños de la calle se descubre una variedad de conductas irregulares. En una lista se presentan 22 síntomas, los cuales son categorizados en tres grupos. En el primero figuran "trastornos en los rasgos del carácter y la conducta" como fuga, negligencia en el cuidado personal, robo, agresiones contra personas y objetos; homosexualidad, intolerancia, frustraciones, insatisfacción, envidia manifiesta, etc. En el segundo grupo de síntomas se encuentran "trastornos de los hábitos y trastornos neuróticos" como: enuresis onicofagia, trastornos del sueño, de la alimentación y del lenguaje, motomanía, fobias, etc. Finalmente, el tercer grupo se refiere a "trastornos del aprendizaje". En el $96.7 \%$ de los niños investigados se detectan dos o más síntomas. Es por esta circunstancia que se puede hablar de una psicopatología de los niños callejeros. Este diagnóstico lo profundiza Ballesteros Rotter a través de algunos resultados de pruebas psicológicas. Según él, más de dos tercios de los niños callejeros tienen un nivel intelectual bajo y de disociación de ideas. El $90 \%$ de los casos muestra una inadecuación con el esquema corporal y con la identificación, imágenes desintegradas e imágenes internas terroríficas. En la mitad de los casos hay pruebas de inadecuación en la orientación de tiempo y espacio, la prospección y falta de adaptación a nuevas situaciones. Las patologías internas de los niños estudiados son las siguientes: se puede observar ansiedades persecutorias y sentimientos de abandono, que no logran manejar adecuadamente. Además, hay incapacidad de contactarse y de ligarse afectivamente, existe pérdida de contacto con la realidad e inadecuación del control yoico.

Ballesteros Rotter se pregunta: ¿qué mecanismos utiliza el Yo de estos niños para defenderse en esta situación conflictiva? Por un lado menciona la disociación que ya se ha indicado. Por otro lado pone de relieve una sintomatología, a la cual se refiere de la siguiente manera:

"Los síntomas neuróticos o de transtorno de los hábitos personales en una proporción del 37.5\%, indican que partes importantes del Yo alcanzaron cierto grado de desarrollo, y que, por lo tanto, los conflictos 
precisamente pudieron ser vivenciados como algo interno, intentándose su manejo utilizando defensas que implican cierta evolución yoica. Sin embargo en la mayoría de los síntomas (62.5\%) podemos ver la expresión de mecanismos diferentes, más regresivos, que denotan la existencia de intensas ansiedades persecutorias. Mediante estos mecanismos se intenta externalizar el conflicto que es entonces vivido predominantemente en el mundo externo, y esto lleva, por una parte, a modificaciones en el Yo, traducidas en rasgos de carácter patológico (desafecto, insatisfacción, negligencia, envidia, etc.), y por otra, a toda esa serie de situaciones psicopáticas ("acting") que caracteriza la conducta de otros niños: vagabundeo, robo, homosexualidad, etc."5

\subsection{El enfoque romántico}

En el centro del enfoque romántico se encuentran aspectos caracterológicos. Se sustenta la opinión que la vida de los niños de la calle sólo puede ser entendida en relación con sus impulsos. Esta forma de ver las cosas es a la que el etnólogo francés Jaques Meunier le da expresión en su libro "Los niños callejeros de Bogotá"6, el cual llama la atención no sólo por sus afirmaciones de carácter científico social, sino también por sus pasajes literarios.

Las exposiciones de Meunier se basan en una inestructurada observación participante, de cuatro meses de duración, así como en entrevistas narrativas con aproximadamente 30 niños callejeros, que transcribe como actas de sus grabaciones. El principal objetivo de Meunier es presentar una descripción exacta del carácter de los niños callejeros ("gamines"); pretende descifrar la infancia callejera ("gaminismo").

Según Meunier, un elemento importante que caracteriza al niño callejero es su renuencia a trabajar. Esto lo atribuye él a su altanería, o simplemente a que no tiene la voluntad de hacerlo. Por el contrario, para él, el niño de la calle es un "parásito", casi nunca es un "bobo". Su especialidad es robar. No se avergüenza porque no conoce la vergüenza. Pero todo esto no es planeado, los niños callejeros viven en una forma completamente impulsiva, le dejan todo al azar. A pesar de esta espontaneidad, tienen algunos rituales, de los cuales deriva su "despreocupación", como por ejemplo, el consumo de drogas. Un estado de depresión reemplaza rápidamente a otro de excitación.7

Contrario a la opinión generalizada, según la cual, el niño de la calle no es un niño, sino una combinación entre niño y adulto, Meunier ve a un niño, que ha tomado la niñez en su propia mano, que vive en el presente y sin futuro, que está satisfecho de ser niño. Es un niño completo. 
A pesar de que los niños de la calle poseen la capacidad de razonamiento y de discernimiento, ellos prefieren seguir lo que les dice su olfato, sus sentimientos, sus ideas espontáneas. Pero esto no tiene fundamentalmente mucha importancia. "El gamín va a la calle como va el pirata al mar".8 En la calle encuentra su "pasión secreta", su "mito": el "gaminismo".

El niño de la calle pierde su hogar como "el judío a su nación". Alejado de él busca a sus iguales. $Y$ es precisamente ésta la característica principal de los niños de la calle: su organización social, la unión en las bandas. El niño de la calle no existe jamás como individuo. Para ser un "gamín" completo, se debe estar con otros. La banda forma parte de la búsqueda del niño callejero. Existe por él y en él. Como (lo atrae) puede explicarse sólo mediante palabras imprecisas y míticas: "Antes de vivenciarla, la gallada (la banda) es una historia que él mismo se narra, un encargo que él se da y asume. (...) El llamado de la gallada no es más que una parte de sí mismo: algo toma vida, un murmullo, una inspiración". 9

El interés del niño de la calle en las bandas no está determinado por algunas características de las mismas. $\mathrm{El}$ no se siente primariamente como parte de su respectiva banda, pues su alegría de vivir consiste al final de cuentas en no depender de nadie. Al mismo tiempo, Meunier hace la importante observación, que hay días en los que las calles céntricas están pobladas por enjambres de niños callejeros, y hay otros días en los que por el contrario, apenas se encuentra alguno. Además, siempre son diferentes niños los que se ven en la calle. Al final de cuentas resulta que un niño puede ser callejero por corto o largo tiempo, pues éste está en un constante ir y venir entre la calle, los albergues, su hogar y la banda. Entonces, el niño de la calle es un "visitante de la calle."10

Por medio de este descubrimiento de la rotación de los niños callejeros, Meunier echa mano del concepto de la contrasociedad: la sociedad de los niños de la calle es una "subcultura de resistencia", una "contrasociedad". Esta última ha sido descrita con detalle por el etnólogo francés Pierre Clastres. Su característica consiste en que no se da en ella ningún ejercicio de poder basado en la coacción en el sentido occidental, puesto que mecanismos sutiles de la contrasociedad han impedido el surgimiento de un poder central, o sea, del monopolio del ejercicio legítimo de la fuerza por individuos o grupos. Este tipo de sociedades primitivas funcionan sin Estado, es decir, que todo en ellas se orienta "en contra del Estado", y por eso son "contrasociedades".11 La forma en que estos mecanismos sutiles impiden en forma colectiva que surja un poder central se infiere, en parte, de las descripciones de Meunier, y es robustecida 
además por Deleuze/Guattari por medio de las tres características siguientes. En primer lugar, es obvia la constante dispersión de los miembros de las bandas, aun las distintas actividades que realizan en conjunto pueden influir en la efectividad de este síntoma. Un segundo aspecto decisivo se puede ver en el hecho de que cada miembro de la banda sostiene una amistad más estrecha con uno o dos miembros del resto, lo cual tiene como consecuencia que, cuando hay desunión, casi siempre no es sólo uno sino varios miembros los que abandonan al mismo tiempo la banda, lo cual trae consigo la disolución de la misma. Finalmente, las difusas fronteras de edad, que obligan a quienes tienen casi quince años a abandonar las bandas, es un medio más para bloquear la formación de un poder central.12

Como una corroboración adicional a su teoría, Meunier utiliza el concepto de las "pequeñas hordas" tomado del sistema del socialista utópico francés Charles Fourier. En este sistema, Fourier descubre el "gusto por la suciedad que la naturaleza obviamente le ha dado a la mitad de los niños $(. . .)^{\prime \prime}$, y la ha sabido aplicar al propósito de la armonización de la sociedad. Esta dependencia de la suciedad no es la consecuencia de una falta de educación o de falta de prescripciones, no, es una realidad natural que trae valiosas ventajas para el equilibrio social. En vez de menospreciar estas tendencias, deben de aprovecharse como la naturaleza nos las da, sin modificarlas. En esta forma Charles Fourier puso de relieve las "pequeñas hordas".13

Meunier utiliza el término de "pequeñas hordas" para las bandas de niños callejeros de Bogotá. Solo que, lo que en la utópica visión de Fourier encuentra su sitio justo, parece "(...) impensable en el equivocado mundo de la civilización. ...Las galladas son pequeñas hordas en un mundo sin armonía".14

\subsection{El enfoque personalístico}

El objetivo del enfoque personalístico es poner de manifiesto el comportamiento sano, competente y de adaptación de los niños callejeros como "indestructibilidad" o "invulnerabilidad". El psicólogo norteamericano J. Kirk Felsmann sostiene este enfoque, el cual apoya en los resultados de investigaciones sobre niños de la calle en la ciudad colombiana de Cali. 15

Felsman elabora un perfil de riesgo para cada uno de los 25 niños callejeros que examina específicamente en un grupo. Por medio de categorías de factores individuales y familiares, Felsman constata para 21 niños de la calle un alto riesgo de psicopatología y para los restantes un 
riesgo mediano. Esta peligrosidad, de por sí grande, se agudiza aun más por la valoración que hacen los padres de sus hijos callejeros como niños extremadamente difíciles y maleducados, por lo que éstos se encuentran con un riesgo adicional de adoptar una función de chivos expiatorios.

Por otra parte, Felsman observa un comportamiento imperturbable y sano de los niños callejeros. Pero también su inteligencia y competencia puede ser evaluada únicamente en su ambiente natural, la calle. Así, por ejemplo, la necesidad de los niños de la calle de poder sostener en público una conversación privada a través de un uso propio del lenguaje - es decir, un lenguaje en parte ininteligible para otros-, no es una expresión de su "mal español" o de su "vocabulario limitado", sino que puede verse más bien como una reacción creativa o de adaptación a las necesidades de su ambiente. De este tipo de formas de comportamiento se desprende claramente la convergencia de capacidades cognitivas, analíticas, sociales y físicas. 16

La buena salud de los niños callejeros puede reconocerse en el hecho de que contrariamente a muchos de los niños que se quedan en los barrios pobres, los primeros están mejor alimentados. Su constitución física es fuerte. En una proporción significativa, Felsman observa un temperamento muy activo, adquisitorio, así como asertorio, con gran inclinación a la búsqueda de aventuras y emociones. Estos rasgos del carácter traen consigo casi siempre deficiencias de adaptación de un niño en un ambiente como el de un salón de clases o el de un contexto familiar numeroso y difícil, pero en una determinada edad y en otro ambiente -como la calle éstos ayudan a la capacidad de adaptación y fortalecen las cualidades de supervivencia del niño.

Según las observaciones de Felsman, la capacidad especial de los niños de la calle consiste en poner a trabajar toda su energía física concentrada en determinados asuntos; su capacidad de carga y su resistencia hasta el agotamiento y su rápida recuperación del equilibrio físico son factores decisivos en el activo manejo de su vida callejera. Felsman argumenta que las cualidades fisiológicas y caracterológicas de los niños de la calle sirven de instrumento a su capacidad de convertir estrategias cognitivas ("coping"17) en conductas reales.

Más aún, según Felsman, no pueden quedar fuera de atención los estadios congnitivos y psicosociales del desarrollo. La edad promedio del grupo de niños callejeros estudiados es de 11 años. Felsman se refiere al psicólogo americano Erik Erikson, para quien la característica dominante de esta edad es la "competencia". Esta es selectiva, directa, persistente y satisface una necesidad interna de interacción con el ambiente. La competencia se encamina a perseguir un sentimiento de eficacia, un placer 
subjetivo, afectivo, que se deriva de la participación competente en el ambiente. En esta edad, la cognición se caracteriza por un período de "operaciones concretas". La interacción con el ambiente y la adaptación al mismo, traen consigo "procesos de solucionar tareas". Con creciente capacidad de planificación y experimentos alternativos de solución de problemas se vuelve posible en el niño la obtención de "operaciones formales", y la capacidad de abstracción. Esta naciente capacidad de "colocarse en la posición del otro" tiene como consecuencia una definición global de la propia persona y de la relación con otros. Lo anterior, puede aumentar enormemente su capacidad de supervivencia en las calles. 18

Para robustecer su teoría de los niños sanos y fuertes, Felsman utiliza los conceptos de "diferenciación psicológica", y de "locus of control" (algo así como instancia de control). Primeramente se distingue entre dos estilos cognitivos: La "independencia de campo" está caracterizada por la capacidad de diferenciar de su todo las partes de un campo, de tal manera, que en su peculiaridad como partes individuales se perciben en formas distintas que las partes componentes del todo. Este tipo de personas funcionan en forma más autónoma, disponen de un concepto básico muy arraigado, así como de un sentido más fuerte de las "particularidades separadas" que las personas que dependen de la visión global del campo, cuyas capacidades de diferenciación son menores o sus mecanismos de resistencia son más globales: éstas tienden a un comportamiento que vaya de acuerdo a las normas sociales. Los niños de la calle se distinguen casi sin excepción por su "independencia de campo", la cual tiene efectos negativos en una situación familiar difícil en los barrios pobres pero tiene efectos de adaptación en el ambiente de la calle, donde las exigencias diarias fortalecen aun más esta predisposición.19

"Locus of control", significa al mismo tiempo una expectativa específica para cada situación y una expectativa generalizada. En las personas "internas" las fuerzas del cambio residen en sí mismas, en las "externas" son predominantes las fuerzas de fuera, las cosas no parecen fáciles de realizar como en el caso de las primeras, sino que dependen primariamente del destino. Precisamente son los niños de la calle, los que destacan con su "locus of control" interno en forma positiva del fatalismo de la masa de los pobres de Latinoamérica.

Felsman concluye, que el comportamiento de adaptación sano del niño de la calle en medio de una familia patológica sólo puede ser explicado a través de su "independencia de campo", de su "locus of control" interno, así como de su capacidad de conservar su autoimagen. Finalmente, en las diferentes pruebas, los niños de la calle se forman una autoimagen que les concede la certeza de que no darán "su brazo a torcer" 20 . En este 
contexto, el abandono del hogar sólo puede entenderse como una decisión activa y consciente del niño de la calle y como un paso para su salud física y psíquica.21

\section{Enfoques respecto al entorno de la sociedad}

En los enfoques al entorno de la sociedad, para la explicación teórica de la infancia callejera, se destacan aquéllos factores que están basados en la forma de la reproducción social. Los defensores de estos enfoques están empeñados en descubrir momentos globales de explicación del fenómeno estudiado. Por eso no es de extrañar que se parta, en su mayoría, de una definición bastante amplia de los niños callejeros; el intento de definición que hace Gutiérrez del niño callejero de Bogotá ("gamín") es sintomático: "Un gamín no es únicamente un niño mendigo; ni un niño vago; ni un niño ratero; ni un niño abandonado que tiene que realizar trabajos eventuales en la calle; ni un niño de conducta irregular o rebelde; ni un desertor o fracasado escolar o de escolaridad irregular o un niño que vive y duerme en las calles de Bogotá; sino alguien que participa de todas esas características simultánea o alternativamente."22

\subsection{El enfoque autoritario}

El enfoque autoritario da como motivo principal para el aparecimiento de niños callejeros el carácter autoritario de la sociedad con todas sus consecuencias que repercuten en las actuaciones concretas de los individuos. Este enfoque es sustentado por el psico-analista colombiano José Gutiérrez, quien no sólo apoya sus afirmaciones en una labor de investigación de muchos años, sino que también puede basarse en una convivencia concreta con un grupo de niños callejeros bogotanos. ${ }^{23}$

Gutiérrez distingue dos grupos esenciales de niños callejeros, los "gamines" y los "no gamines" o "chupagruesos". A los primeros los ve caracterizados principalmente por los siguientes comportamientos: son enemigos de los ricos y tienen una posición altiva. Frente a los adultos muestran siempre su conducta consistente, que ellos mismos clasifican como "ser firmes". Actúan en forma impulsiva, no toleran ninguna injusticia. Son inconformes.24 Los niños del segundo grupo, por el contrario, son más pacientes, disponen de más sentido de la realidad y actuan con más reflexión, y pueden tolerar por mucho más tiempo el descontrol de otros. 25

Gutiérrez hace la observación de que los niños de ambos grupos, si bien pasan su existencia en las calles de manera muy parecida, viven sin 
embargo en mundos completamente diferentes. Mientras los "gamines", que viven en bandas, se han aislado a través del desacato a las normas de los adultos de la sociedad establecida y han fundado su propio mundo con sus propias convenciones e ideales, los "chupagruesos" se entregan al mundo de los adultos, por lo cual tienen para los "gamines" la fama de "traidores". Precisamente por su forma de ser tan sumisa y de "mosquita muerta", los "chupagruesos" son odiados por los "gamines".

Mientras que Gutiérrez ve a los "chupagruesos" como víctimas indefensas, maltratadas, que se adaptan a las estructuras autoritarias inhumana de la sociedad, a los "gamines" los ve con un especial interés, puesto que éstos intentan precisamente escapar del autoritarismo. Las historias familiares de los niños callejeros, las cuales examina Gutiérrez con detenimiento, demostraron, a la par de un clima de frialdad, sobre todo fuertes rasgos de sadismo de los fuertes frente a los débiles, que es la consecuencia del mal uso del poder. Las víctimas de los arranques de furia del colérico padre o también de la madre - quienes son ellos mismos golpeadas por una sociedad que produce grandes tensiones en los individuos precisamente por su autoritarismo- son los niños, quienes deben aguantar los peores maltratos. Esto los lleva a escapar de su hogar. Los "gamines" son lo suficientemente fuertes para unirse y construir una "contrasociedad" con sus propios símbolos y rituales, que se opone a la cultura "oficial". La característica decisiva del "gaminismo" consiste precisamente en la protección que a cada uno le brinda la unión de los niños callejeros frente al peligro con que le amenaza una familia y un mundo de adultos que son sus enemigos - por ser autoritarios. 26

Pero ni los "gamines" se pueden librar en su propia vida en común de la influencia de una sociedad autoritaria. También aquí descubre Gutiérrez rasgos sadistas y masoquistas, que se manifiesta en la brutal explotación de los menores por los mayores, que a veces termina en violación homosexual. Aun más, la llamada "requis" es un típico ejemplo donde los niños callejeros fuertes con más experiencia atacan a los débiles inexpertos. Esto le produce un gran placer, pues al fin y al cabo ellos mismos han sido víctimas alguna vez de este tipo de actuaciones. Pero todo esto no es más que un reflejo de las muchas formas de autoritarismo de la sociedad colombiana, de los "defectos" de los adultos. 27

En otras formas de comportamiento constitutivas del "gaminismo", Gutiérrez encuentra también una resonancia patológica. Así como por ejemplo en la acción del "achante", en la cual el niño de la calle se retrae triste, deprimido y agotado, no toma alimento y rechaza todo tipo de relación; algunas veces esto atrae consigo actos autodestructivos. También puede terminar esto en la "recocha", una mezcla de juego peligroso 
y provocación abusiva, en la cual se manifiesta la rebelión contra los adultos y que va acompañada por el consumo de drogas, que al final conduce a comportamientos agresivos y/o delictivos frente a la autoridad social. El juego rebelde y pesado de los "gamines" toma con frecuencia formas incontrolables, que generan en los adultos provocados una forma de comportamiento casi siempre autoritaria y represiva. Gutiérrez observa que en su trabajo con los "gamines", él mismo cayó una vez en el autoritarismo. La "recocha", la rebelión de los "gamines" es inconciliable con el autoritarismo social imperante en Colombia. Finalmente concluye que la "recocha" de los "gamines" y las respuestas autoritarias a ella por parte de la población colombiana represeritan un círculo vicioso social, cuyos procesos recíprocos que van de unos a otros encierran el "gaminismo" y lo hacen incurable. 28

\subsection{El enfoque modernizante}

En el enfoque modernizante se buscan las causas del fenómeno de la infancia callejera en aquéllos factores que resultan de procesos sociales de transformación. En especial se hace referencia a la desorganización social que, según se sostiene, se origina de la industrialización, los movimientos migratorios del proceso de urbanización y la explosión demográfica que se dan en una sociedad en vías de modernización. Los niños callejeros surgen como un producto de una situación global de crisis social, en la cual un modelo social antiguo está siendo reemplazado por uno nuevo.

Varios sociólogos y antropólogos han recurrido a este enfoque. En él se destacan principalmente tres tesis, que pretenden dar respuesta al problema de por que los niños terminan en la calle.

Está la tesis presentada por Granados Téllez de la influencia nefasta de un vecindario de delincuentes. $29 \mathrm{El}$ resultado de su investigación es que la mayoría de las familias de los niños callejeros de Bogotá son familias inmigrantes provenientes de otras ciudades colombianas que, en la búsqueda de mejores condiciones de vida, se exponen en los céntricos tugurios a la vecindad directa con criminales. Tanto las familias inmigrantes como los criminales, prefieren este tipo de viviendas céntricas por diferentes motivos: en primer término, para conseguir trabajo rápido, y en segundo, para ubicarse en las zonas de la ciudad más frecuentadas y más adecuadas para robar. Los niños de familias pobres que no son delincuentes observan que algunos vecinos se visten bien, sólo trabajan a veces, llegan tarde a casa y por las mañanas se levantan tarde. Pronto estos niños se dan cuenta que estos individuos ganan "dinero rápido", o sea, robado. Puesto que a los niños es necesario que los valo- 
res les sean transmitidos, y las personas a las que les corresponde su educación en estos tugurios no lo hacen, es natural que estos niños sigan el ejemplo de los criminales; se declaran solidarios con ellos y asumen sus normas. Es en esta forma que los niños llegan a las calles en compañía de los criminales, donde éstos los inducen a los robos y finalmente adoptan la vida en círculos de niñes calleros.

Una segunda tesis expuesta por Muñoz/Pachón30 hace referencia a los conflictos culturales en los que se encuentran los inmigrantes del campo en la ciudad. Pues la mayoría de los niños callejeros estudiados son descendientes de padres que provienen de un ambiente rural y están marcados culturalmente por el mismo. En el desconocimiento de las reglas del juego de la ciudad, tienden a aferrarse a los ideales del campo. Por esta razón les inculcan a sus hijos normas incompatibles con el clima de competencia de la ciudad. Otra consecuencia de los conflictos culturales es su estado psíquico tan cambiante. Todo esto al final tiene como resutado que la educación que dan los padres se reduce a órdenes, castigos e insultos. Aún más, el comportamiento educativo es inconsistente, los niños son fuertemente castigados por pequeños errores, mientras que negligencias o malos comportamientos graves quedan muchas veces impunes. Ello impide que el niño comprenda que es lo que tiene que hacer o dejar de hacer. En estas circunstancias no está en capacidad de desarrollar una noción de lo que es la relación causa-efecto. Finalmente, este tipo de niños tan confundidos tienden a liberarse del inadecuado control de los adultos a través de la fuga; se puede decir que la familia empuja al niño a la calle.

Una tercera tesis del enfoque modernizante 31 consiste en la afirmación de la inestabilidad interna de las familias necesitadas que no están comprendidas en el sistema de seguridad social y cuyos hijos inevitablemente terminan en la calle, pues los llamados padres "esporádicos" o padrastros, son los que con frecuencia entran en conflicto con los hijos de uniones anteriores de las madres, lo cual termina casi siempre en agresiones físicas de los primeros contra los segundos. En la elección entre los "molestos" niños y el compañero de vida, la madre se decide por éste. Esto trae consigo la huida o abandono de la casa materna por parte de los niños, que son un estorbo para la nueva unión, y por consiguiente la vida de éstos termina en la calle.

\subsection{El enfoque socioestructural}

En el enfoque socioestructural se hace referencia a las disfunciones del siste-ma social. El interés se centra en aquéllos aspectos que están en relación con la forma de vida de una parte de la población que no puede 
satisfacer sus necesidades básicas más que en forma precaria. Los defensores del enfoque cuestionan el injusto "status quo" social. Por otra parte, muchos autores hacen una aplicación del enfoque socioestructural en relación a la realidad latinoaméricana.

El punto de partida de la argumentación es la vida cotidiana concreta de la clase de los "marginados", que se caracteriza por la ardua lucha por sobrevivir que requiere de un esfuerzo supremo y que prácticamente involucra a toda la familia. Aquí juegan un papel importante los niños, quienes desde muy temprano deben asumir la dura tarea de aportar a la manutención de la familia. Así ocurre casi siempre de tal manera, que ellos, acompañados de sus padres o solos, deben dedicarse en la calle a alguna actividad del sector informal, como por ejemplo, lustrar zapatos, vender periódicos, lavar carros, etc. De manera que se trata de "niños en la calle", que se encuentran en ella sólo para trabajar y regresan con regularidad a sus familias.

Pero con el tiempo, estos niños que trabajan en la calle van ganando cada vez más autonomía. Al mismo tiempo, establecen contacto con otros niños que tienen más tiempo de vivir independientemente en la calle y que están organizados en grupos. Estos contactos se intensifican cada vez más, la permanencia de los "niños en la calle" se va dando en períodos más largos, hasta que al final se quedan completamente en la calle y se convierten en verdaderos "niños de la calle", que prácticamente ya no regresan a su familia. La socialización ocurre, pues, en el grupo de niños callejeros. Los niños que viven solos en la calle son despreciados por la sociedad. Especialmente lo perciben cuando ingresan en instituciones estatales, donde lo único que reciben es arbitrariedad y malos tratos. A la larga, al niño de la calle no le queda otra cosa que incorporarse al mundo de la criminalidad o de la mendicidad. Algunos pocos logran talvez adoptar la existencia de un trabajador "marginal".32

Las verdaderas causas de la existencia de niños callejeros no puede encontrarse en padres irresponsables o aun en los niños callejeros mismos como sujetos de "comportamiento desviado", como lo hace la teoría sociológica clásica. Las verdaderas causas estan arraigadas en la estructura social que reproduce constantemente injusticia y desigualdad. Los niños de la calle son la "creación" de un orden social, cuya dinámica siempre provoca que haya unos privilegiados y otros menos privilegiados o víctimas. En una estructura social tan injusta, siempre trabajan mecanismos ideológicos de conservación de un "status quo", que reproduce en forma permanente el esquema de la opresión. A los hijos de los oprimidos se les privó de la "niñez" y de la "juventud". Como excluidos y discriminados por el sistema, deben tomar la vía del "destierro social". 
Los niños callejeros, que al principio eran completamente normales, han tenido que sufrir defectos en la personalidad. La degradación de origen social del individuo lleva finalmente al consumo de drogas y otras conductas destructivas (robo). En una subcultura, los niños callejeros desarrollan reacciones de defensa -antivalores y agresiones contra la sociedad "oficial". La subcultura de la calle les permite a los niños de la calle vivir en la sociedad de la que fueron expulsados. 33 La existencia de los niños callejeros es la expresión de que hay injusticia: "Son como la espuma que produce el jabón; donde existe una sociedad que no funciona, allí hay gamines". 34

\subsection{El enfoque sociohistórico}

El enfoque sociohistórico considera la aparición de niños callejeros como el producto de una dinámica sociohistórica que se remonta a la Conquista. Según éste, los pecados del tiempo de la conquista ibérica trajeron una sombra, como una especie de maldición sobre el continente conquistado, de la cual los latinoamericanos no se han librado todavía. Esta concepción es sustentada por el sacerdote español Alejandro García Durán ("Padre Chinchachoma"), quien tiene tras de sí una larga labor práctica con niños callejeros en México.

En el "retrato robot psicológico del niño de la calle" García Durán llega a constatar la "psique fuertemente lesionada" del niño callejero. Esto lleva a una fuga permanente, al "cotorreo", lo cual significa "(...) no pensar jamás, a no pararse nunca. A olvidar el pensante que hay en uno y adornecer el alma con el primer sonido, no importa de donde venga". $35 \mathrm{El}$ niño callejero ha nacido para huir, lo hace a la edad de siete años y en la calle encuentra su único camino: el "cotorreo". Aquí satisface sus instintos, a los cuales pertenece, entre otros, el consumo de drogas; cerca del $80 \%$ de los niños callejeros hacen uso de este medio. Los niños callejeros que trabajan son obligados a llevar a su hogar una "cuota diaria" de dinero. Si ésto no sucede, el $60 \%$ de ellos se expone a maltratos de sus padres. $\mathrm{Ni}$ aún en las instituciones se interesa nadie por ellos, sólo se les golpea. Pronto se desprecian a sí mismos. Finalmente van a parar nuevamente al "cotorreo", escapan de sus escapes. 36

En otra parte del trabajo se concretiza el "análisis de la realidad" de García Durán. Se habla de la dinámica de la represión y expresión de los niños callejeros, la que se supone ser tan lógica como una ley física. Del esquema que lleva por título "Radiografía psíquica" se desprende que: Cada efecto represivo por parte de la sociedad provoca en el niño de la calle situaciones emocionales negativas específicas, de las cuales él saca la conclusión de que es malo, que no vale ("yo no valgo") y finalmente 
se desprecia. Este autodesprecio transforma la represión causada por la sociedad en fuerzas tales, que se convierten en acciones negativas contra la sociedad. Este esquema de "input social" - "output individual" se ve en cada individuo así: La atención suficiente del grupo primario (familia) produce miedo y sentimientos de culpa que trae consigo la incapacidad de amar y la tendencia en la vida sexual a la violación. La obligación económica impuesta al niño callejero por sus padres equivale a una "sequedad" emocional y causa la delincuencia. La violencia sufrida en el hogar así como en la calle, y la arbitrariedad por parte del Estado, provoca el temor y la inseguridad, que de acuerdo a los procesos de autodesprecio, se traduce en el peor de los casos en violencia mortal, o en desconfianza frente a cualquier autoridad y en consumo de drogas. El niño de la calle que se desprecia a sí mismo llega a la conclusión que, no importa lo que haga, no tiene nada que perder.37

¿En qué ve, entonces, García Durán los motivos para la existencia de los niños callejeros, psíquicamente lesionados y autodespreciados? Para encontrar la causa, el autor aborda la historia de México. El pueblo virgen de los indios estaba organizado aristocrática, social y religiosamente. Con la venida de los españoles, este organizado y poderoso mundo comenzó a autodespreciarse. Puesto que esta venida había sido anunciada en vagas profesías y malos augurios, fue afrontada como el inexorable destino. El mundo español que llegaba se enfrentó a los indios con muchos errores, principalmente con uno: Sólo vinieron hombres que arrastraban miles de batallas tras de sí. Gracía Durán se cuestiona, qué imagen les transmitieron estos españoles - sus antepasados- a los indios: “De relajo. (...) De violación. Violación de cultura, de monumentos, de mujeres, de vida. 38

Los indios tomaron el papel de esclavos. Surgió un mundo abyecto de la incomprensión, de la dominación absoluta. Un mundo de amos y esclavos, un mundo de "machistas", en el cual el hombre asedia a muchas mujeres, con la intención de procrear de ser posible muchos hijos como reafirmación de su hombría y no como expresión de amor. Se creó un mundo de la riqueza rápida, en el cual también los sacerdotes se volvieron señores de los esclavos indígenas, atándolos de este modo a un poder "mítico". Un poder que era aun más fuerte que el de los crueles conquistadores. En este contexto, el padre García Durán no omite mencionar el abuso de poder de un clérigo homosexual que se divertía ordinariamente con los niños callejeros, manteniendo con ellos relaciones sexuales. 39

En el actual México se desprecia todo lo indígena y todo lo español. ¿Qué les queda a los mexicanos? El pueblo mexicano se encuentra en la 
adolescencia, aún no se ha encontrado así mismo, aún no ha aceptado que tiene una doble herencia, no ha encontrado su identidad en la mezcla. El mexicano no está seguro de su hombría y por eso practica el sexo con varias mujeres. Por otro lado, el esclavo actual se libera de los azotes de su antiguo amo descargándolos en los más débiles: su mujer, sus hijos.

\subsection{El enfoque sociocultural}

El enfoque sociocultural considera a la infancia callejera en el contexto de una realidad social, que está marcada por el antagonismo de estructuras familiares matrifocales y patrifocales. La existencia de niños callejeros es vista como una consecuencia lógica de prácticas funcionales de educación de las familias matrifocales, que en una sociedad predominante patrifocal son reprimidas. Este enfoque es sustentado por el psicólogo norteamericano Lewis Aptekar, que desarrolla sus afirmaciones sobre la base de una observación participante y de pruebas psicológicas con 56 niños callejeros de la ciudad colombiana de Cali.

Aptekar ayudado por los resultados de las pruebas pinta el cuadro de un niño de la calle completamente normal que actúa racionalmente. El cociente intelectual de la gran mayoría de los niños callejeros examinados $(69 \%)$ está en un nivel promedio normal. Según Aptekar, sólo en una cuarta parte, el estado emocional se encuentra en el campo patológico, mientras que en la mitad de ellos incluso el Ego funciona bien.40

Muchas de las conductas observadas en la calle o en los albergues, Aptekar las interpreta en forma similar a como lo hiciera su colega Felsman,41 como un comportamiento racional y eficiente de los niños callejeros. Aptekar contradice muchos aspectos de la creencia popular sobre los niños de la calle, las cuales considera él como "mitos". La homosexualidad de los niños de la calle, al parecer ampliamente difundida, en realidad no existe y más bien es algo que ellos desdeñadan. Asimismo, Aptekar niega el alto consumo de drogas y los robos que se les atribuyen a los niños callejeros. Su vida en grupo no es parte de una subcultura criminal, sino que más bien les ayuda en la incorporación al mundo laboral y a la vida de la subcultura de pobreza urbana establecida. Aptekar rechaza también la concepción, a su parecer errada, de que atraviesan un proceso de degradación personal con la vida callejera permanente. Más bien los valores mejorados desde el punto de vista emocional de los niños callejeros mayores que examinó muestran que la vida en la calle en relación al estado emocional de los niños tiene más consecuencias favorables que dañinas. 42

Aptekar considera a la infancia callejera desde una perspectiva de 
desarrollo y divide a los niños de la calle en dos grupos: los que se encuentran antes de la pubertad y los que se encuentran después de la misma.

En el primer grupo, Aptekar distingue -como lo hizo antes Gutiérrez43 - entre niños callejeros independientes, arrogantes, sagaces y niños callejeros dependientes, sumisos, inseguros ("gamines" y "chupagruesos").

A los niños callejeros que se encuentran después de la pubertad, Aptekar los divide en tres grupos. Los excelentes resultados de las pruebas del $42.9 \%$ de los "afortunados", permiten concluir que superaron con éxito la transición a la edad adulta y se convirtieron en personas satisfechas y productivas de la sociedad. El $23.8 \%$ de los "desamparados" arrojaron los peores resultados; de hecho dieron muestras de crisis psíquica y emocional. Estos no están en la capacidad de velar por sí mismos y necesitan de una atención permanente. Finalmente, los resultados promedios del $33.3 \%$ de los "sobrevivientes" demostraron que éstos pudieron sacar adelante sus vidas, para lo cual sin embargo necesitaron hacer uso de toda su energía.44

Aptekar saca de su material la conclusión de que talvez una cuarta parte de los niños callejeros termina en una u otra forma "improductiva" (por ejemplo como alcohólico, enfermo mental). A otra cuarta parte le pronostica una vida exitosa, en comparación a los niños que nunca abandonaron los barrios pobres, mientras que al resto lo pone en la línea de la "funcionalidad" total, es decir que son completamente "normales". 45

Sobre la base de estos datos, Aptekar llega a una explicación teórica. Primeramente contradice el mito de que los niños callejeros provienen en su mayoría de familias que los maltrataron o abandonaron. Más bien, los niños de la calle descienden de familias matrifocales, en las cuales la madre es una mujer independiente y activa, la personalidad predominante, el centro de la familia. El elemento paterno en estas familias tiene una existencia marginal y no juega ningún papel en la educación de los hijos, es decir que la mujer no lo involucra en ella. Los matrimonios en las familias matrifocales sólo pueden entenderse como uniones inconsistentes, que descansan sobre arreglos no sólidas, que las mujeres rompen cuando piensan que las necesidades de la familia - esto es de la madre y sus hijos- están siendo afectadas en forma negativa por parte de los hombres.

En estas familias, los varones son estimulados desde muy temprano a buscar la independencia y a ganarse la vida por sí solos, aun cuando sea en las calles. Lo que siempre, en forma errónea, es considerado como 
abandono y descuido de los niños, en la realidad no es nada más que una forma de educar a los niños que de manera muy consciente pretende transmitir a los niños independencia y seguridad en sí mismos en la existente subcultura de pobreza urbana. En la dinámica de las familias de niños callejeros se trata de un enfoque funcional de la educación de los hijos; incluso en algunos casos la vida callejera llega a tener su valor en la educación. Con frecuencia es también así que los hijos mayores asumen una significativa parte de la responsabilidad en la educación de los hermanos menores, lo que exige el desarrollo de un comportamiento social responsable. La infancia callejera, entonces, no es más que la expresión de prácticas normativas de educación de los hijos en las familias matrifocales. 46

La posterior ausencia periódica y después permanente de los niños de las familias matrifocales es equivalente a la anterior búsqueda.de su correspondiente identidad, a una parte muy normal desde el punto de vista subcultural del desarrollo en el cual los grupos ya existentes en las calles les ayudan mucho. Por lo demás, la infancia callejera no se limita únicamente a los varones; también hay niñas que, ciertamente en forma errónea, sólo son vistas como prostitutas. El que haya menos niñas que niños callejeros se puede atribuir a que, en las familias matrifocales, las niñas tienen en la madre el ideal de una mujer independiente y por eso, no necesitan tanto de buscar su identidad en la calle como los varones. 47

A los niños que han llegado en esta forma a la calle, entonces, se les ha enseñado a andar su propio camino, sin sacar ventajas de relaciones personales o "palancas". Los niños de la calle presentan en su vida callejera una existencia moderna, en el sentido que siguen los principios de una sociedad basada en principios meritórios. Esto está en franca contradicción con la sociedad colombiana dominante. Las familias matrifocales -que tienen origen africano- $y$ sus hijos, representan un gran peligro para el "Establishment" político en Colombia, que descansa sobre estructuras familiares patrifocales - de origen español-, en las cuales quien domina es el padre y los hijos son dependientes por largo tiempo. Aquí imperan principios que no están basados en méritos, y de esta forma también antimodernos, o sea aquéllos que tienen su origen en las relaciones personales. La infancia callejera se desarrolla en el trasfondo de esta lucha entre dos culturas con diferentes organizaciones familiares, la cual encontró su primera expresión en la guerra civil colombiana "La Violencia" a mediados del siglo veinte. Después de esta guerra civil, Colombia se modernizó y adoptó los primeros principios meritórios.

Los muchos mitos o concepciones erróneas sobre los niños de la calle provienen del intento de defender la estructura tradicional patrifocal frente 
a los cambios de sistema social colombiano. Por eso la reacción de los gobernantes con respecto a la infancia callejera es únicamente tratar de cercenar la temprana independencia de estos niños, lo cual equivale a un control precario sobre una sociedad nueva basada en principios meritórios que está en formación. 48

\section{Críticas a las teorías e investigaciones expuestas}

La exposición que hemos hecho de los resultados empíricos y las explicaciones teóricas de la infancia callejera ha demostrado cuan diversos $y$, en parte, contradictorios pueden ser los enunciados de los distintos enfoques. Como observador atento, se debe uno plantear la interrogante, ¿de si por fin los niños de la calle están enfermos o sanos, si son homosexuales, drogadictos, maltratados, abandonados o si son muy normales y actuan racionalmente. ¿Se degradan, entonces, los niños en la calle, o lo que es lo mismo, se aumenta aun más su supuesta patología? ¿O debe, por el contrario, evaluarse su vida callejera en forma positiva, significando esto que en ella se convierten en personalidades, en personas productivas y satisfechas? ¿Es su unión en grupos o bandas una prolongación poco espectacular del mundo de los pobres, o representa una subcultura o, aún, una contrasociedad?

Estos resultados contradictorios producen una gran confusión. Pero contradicciones hay no sólo entre los diferentes diagnósticos y explicaciones sobre niños callejeros. Las contradicciones están en parte en ellos mismos. Por eso no es raro el hecho de que se caractericen por una serie de distorsiones e inconsistencias. En la siguiente discusión se pretende tratar más de cerca estos síntomas a través de ejemplos concretos y al mismo tiempo obtener una base con orientación a los problemas para "desenmarañar" y "aclarar" el tema de los niños de la calle.

\subsection{El problema de la falta de distancia analítica}

Algunos autores ya han hecho referencia a lo difícil que es, en el tema de los niños de la calle, guardar la distancia con el objeto de estudio, que es tan necesaria en la investigación científica. Por ejemplo, Beltrán Cortés habla de que las reacciones al problema de los niños de la calle originan un "pensamiento catatímico", que se dirige más por los sentimientos que por la razón.49 Felsman habla del problema de la conmoción ("sympathy"), que se llega a sentir en muchas investigaciones y proyectos con niños callejeros lo cual lleva a conclusiones limitadas y a una política social inadecuada. Felsman plantea a los científicos y políticos sociales la exigencia de adoptar una posición empática en relación con una visión críti- 
ca de investigación. 50

Lo que se tratará de demostrar a continuación es que la mayoría de investigadores que han abordado el tema de la infancia callejera no han cumplido esta exigencia, y no han podido resistir la tentación de dejarse llevar por el sentimentalismo del objeto de la investigación, o sea, dejarse arrastrar por una determinada tendencia.

\subsubsection{La tendencia victimizadora}

Se entiende por tendencias victimizadoras, aquéllas que ven a las personas investigadas ante todo como víctimas, ya sea del ambiente o de las circunstancias. Haciendo una apreciación más profunda de la investigación sobre la infancia callejera, se pueden reconocer especialmene tres formas de observación, de las que surgen tendencias victimizadoras.

a) Niños callejeros como receptores de caridad y compasión

Esta forma de observación tiene su origen en el trabajo social diario con los niños de la calle, el cual se basa fundamentalmente en intensas formas de convivencia. Debido a este involucramiento directo del trabajador social, es inevitable que se toque en gran medida su esfera sentimental. Este es, por ejemplo, el caso cuando se encuentran niños callejeros que han sido maltratados o que están bajo el efecto de las drogas. Las mismas emociones se despiertan frente a las condiciones de miseria en que viven las familias de los niños callejeros en los barrios pobres. Algunos casos "graves" afectan tanto a los trabajadores sociales, que les quedan gravados por mucho tiempo. Se generalizan vivencias individuales "terribles" y se sacan conclusiones apresuradas. Hay casos diferentes que siempre son incluidos en la misma categoría de la miseria, la explotación y el maltrato. Se adopta muy rápidamente la posición del afectado. También para actuar, se tiende a satisfacer más las necesidades inmediatas, que a considerar las consecuencias de las mismas. Entonces, es muy frecuente que el resultado del trabajo social sea muy distinto de lo que originalmente se pretendía. Siempre está presente el riesgo del paternalismo o de una forma de proceder puramente caritativa; con frecuencia los trabajadores sociales se convierten en "auxiliadores sin auxilio".

Considerar a los niños callejeros como receptores de caridad y de compasión trae consigo una tendencia victimizadora, que se puede encontrar, sobre todo, en los enfoques en los que la investigación empírica está en estrecha relación con la práctica del trabajo social, como en el caso de García Durán. 51 
b) Niños callejeros como niños de clase media discapacitados

Esta percepción se basa en una concepción del mundo, en la que la infancia está ligada a ideas muy específicas, como son las de una fase de desarrollo en la cual se debe garantizar dirección y protección por parte de los adultos respondables de la educación. Al niño no puede hacérsele responsable por sus actos, pues no se encuentran todavía en el proceso de maduración. La culpa sólo se le puede atribuir siempre al adulto responsable.

Según esta concepción el fenómeno de la infancia callejera debe ser una perversión en sí. Ni tan siquiera puede pensarse, de acuerdo a ella, en niños que viven solos en la calle, éstos deben considerarse inevitablemente como víctimas de sus padres irresponsables Esta visión parte del modelo de infancia de una clase media occidental, según la cual los niños siempre deben estar cuidados por los padres. Cuando se traslada a ese tipo de estratos sociales, en los que la infancia juega un papel muy distinto que en la clase media, dicha visión conduce inevitablemente a una tendencia victimizadora. Los niños de la calle como niños de clase media impedidos no pueden ser concebidos de otra forma que como víctimas. Esta tendencia victimizadora se pone de especial manifiesto, por ejemplo, en Gutiérrez de Pineda y otros, en cuyo esbozo de investigación de la integración familiar, se mide a las clases bajas con cualquier ideal de comunidad conyugal de las clases privilegiadas colombianas. 52 do"

c) Niños callejeros como punto de mira del "hombre blanco sollozan-

El francés, Pascal Bruckner, habla del problema, bajo la clave del "Síndrome del Calcuta", acerca de como se comporta el europeo satisfecho ante el cuadro de la miseria en el "Tercer Mundo". Atormentado con sentimientos de culpa y malestar no superado, vuelve siempre la mirada a la historia colonial, en la cual el "Tercer Mundo" aparece siempre como explotado. Este "sollozo del hombre blanco" podría llevarlo incluso a odiarse a sí mismo. La consecuencia de esto es una relación completamente irreal del "Primer Mundo" con el "Tercer Mundo"; se despierta una compasión que es completamente improductiva y no sirve de fundamento para un verdadero encuentro con una cultura extraña. 53

Tomamos este "sollozo del hombre blanco", entendido de esa manera, para caracterizar una tendencia de observación que se vuelve manifiesta en algunos teóricos y prácticos del "Primer Mundo", que pretenden acercarse al tratamiento del problema de los niños callejeros del "Tercer Mundo", en este caso de Latinoamérica. No se pueden divisar en forma individual las consecuencias de gran alcance que trae consigo este 
tipo de complejos de culpa tan abrumadores. Lo que sí se sostiene aquí es que, en la consideración del tema de la infancia callejera, provocan una especial tendencia victimizadora, lo cual se puede ver más claramente en el español García Durán, cuyo libro habla únicamente de la miseria y los maltratos que sufren los niños callejeros. 54

\subsubsection{La tendencia glorificadora}

Se entiende bajo tendencias glorificadoras, aquéllas en la cual las personas estudiadas son "reconocidas" o admiradas como héroes, cuyo ejemplo es imitable. Partiendo de la literatura especializada existente, se manifiestan tres tipos de tendencias glorificadoras.

a) Niños callejeros como revolucionarios

La percepción del niño callejero como revolucionario tiene tradición. En la novela de Jorge Amado titulada "Capitaes da arreia", el niño callejero Pedro Bala se convierte en un líder político revolucionario.55 También en la literatura soviética, los niños callejeros rusos ("Besprizornyj) fueron idealizados como prototipos revolucionarios y pilares de la revolución de octubre. Ya entonces, el pedagogo ruso Anton S. Makarenko, hacía todos los esfuerzos posibles por mantenerse alejado de las "confusiones" y "perspectivas embriagantes" que estas idealizaciones implicaban.56

Aun en la literatura especializada de Ciencias Sociales que se ha presentado, se revela claramente esta concepción del niño callejero revolucionario. Aptekar habla de una "perspectiva profunda" (keener insight) de los niños de la calle, tipologizados por él como "gamines", en las circunstrancias ocultas de la vida ("nature of life") de su país: "Su educación les ha enseñado (a los "gamines") a originar cambios, y con ello a manejarlos, -mucho antes que a adecuarse al status quo e impulsarlo-, que talvez no poco se parecen a los cambios radicales que exigen las guerrillas: una distribución más justa de la riqueza y de la tierra, acceso al trabajo según criterios de calificación, en vez de criterios basados en la procedencia familiar o en las relaciones, y la eliminación del gran abismo que existe entre pobres y ricos." Aptekar cree en una relación paterno-filial entre los ex-niños callejeros y sus hijos, que se basa en la igualdad, la independencia y la amistad.57 También Gutiérrez glorifica a los "gamines" como "pequeños guerrilleros urbanos" que elaboran un "plan subversivo". 58 Debe considerarse problemático el hecho que los autores que se han mencionado, que glorifican a uno de los tipos de niño callejero ("gamín") como revolucionario, obviamente no tienen escrúpulos en presentar al otro tipo en forma un tanto despectiva como "chupagrueso". 


\section{b) Niños callejeros como profetas}

Partiendo de un fundamento utópico, el niño de la calle es considerado como profeta. Esta forma de apreciación se puede encontrar especialmente en círculos religiosos, que proyectan en los niños callejeros ideas visionarias. En este utopismo, para lo único que sirve la realidad es para considerar aspectos de la misma en interés de la visión. Los defensores de esta posición se apartan en forma muy evidente de la ciencia, pues el objetivo de ésta es, a través del uso de la razón, desenmascarar los visiones o mitos como tales. Al final de estas visiones se encuentra finalmente la creación de un "hombre nuevo", de una "sociedad nueva": "El gaminismo expresa que hay injusticia y reclama una actitud cristiana que modifique esta situación, que realice el Reino de Dios. (...) Es una gran nueva de salvación que exige un cambio radical de la conciencia del hombre y de las relaciones entre los hombres. (...) Deben encaminar su acción a la creación de un hombre nuevo y de una sociedad nueva."59 En otra parte se sustenta la concepción del "menor" —así se le llama al niño pobre basileño, inclusive el niño callejero- como "solución permanente y efectiva para los problemas sociales".60

\section{c) Niños callejeros como representantes de un mundo sano y salvo}

Esta forma de ver al niño callejero como representante de un mundo sano y salvo tiene sus raíces, en primer término, en la crítica a la cultura. En el enfoque romántico de Meunier se pone de manifieso que el autor vuelve la vista hacia atrás, habla de los "buenos viejos tiempos". El glorifica el brote de niños callejeros como algo que en su patria, Francia, ya casi no hay, debido al avance del modernismo y el progreso -el "equivocado mundo de la civilización". Precisamente de este desarrollo quiere escapar el occidental Meunier, cansado de la civilización, anhela un mundo en que todavía quede algún resto de verdadera humanidad. El autor cree detectar ésta en la pasión de los niños callejeros ("gamines") de Bogotá, cuya verdadera humanidad no ha sido perturbada todavía por el sistema moderno. Pero aun aquí ve Meunier ya la destrucción de los vestigios del mundo que él reconoce como sano y salvo: "Todo lo que es nuevo parece conspirar contra ellas (las bandas de niños callejeros): empezando por la policía hasta la píldora, desde la vigilancia con cámaras de televisión en los almacenes hasta estos malditos automóviles, los modelos gringos o japoneses, que ya no tienen aquellos parachoques que les sobresalen y sirven de asiento plegable, y que tienen seguro en el tanque de gasolina. (...) Resumido: el progreso es antigamín."61 
En este contexto es interesante, que el mismo fenómeno de los niños callejeros colombianos sea interpretado tan opuestamente, dependiendo de las distintas tendencias de apreciación. Mientras para Meunier el que los niños callejeros viajen subidos en los parachoques de los vehículos es una expresión de su pasión -que ya sólo se puede disfrutar en lo que queda de un mundo sano y salvo-, Nicoló lo interpreta, bajo la influencia de la tendencia victimizadora, ("niños callejeros como receptores conmovidos de caridad") como una nefasta consecuencia del consumo de drogas, por lo cual los niños callejeros son arrollados con frecuencia.62

Finalmente cabe mencionar que las distintas variantes de las tendencias victimizantes y glorificadoras no son válidas científicamente. Esto no quiere decir que sean generalmente inadmisibles en el tratamiento del tema de los niños de la calle y que deban ser combatidas. Pues en otros campos, como por ejemplo en la literatura, pueden jugar un papel muy importante y desencadenar la fuerza creativa.

\subsection{El problema de las teorías preconcebidas}

A continuación se pretende analizar la forma de proceder de los investigadores, consistente en "comprender" y "explicar" la realidad de los niños callejeros con una determinada teoría que fue concebida antes del verdadero levantamiento de datos. En el caso de algunos investigadores, este proceder de acoplar los datos a la fuerza con la teoría, se pone de manifiesto en las contradicciones de fondo, que saltan a la vista al hacer una lectura detenida.

En Jaques Meunier se evidencian claramente las contradicciones. Mientras que al principio de su libro subraya que lo típico de los niños callejeros que él llama "gamines" es su renuencia al trabajo - lo cual es reforzado varias veces a través de todas sus exposiciones con la descripción de los robos de los "gamines"-, de pronto al final del libro se habla de una banda de "gamines" que trabajan todo el día en un basurero para ganarse la vida. Al final, lo que Meunier pretende en este pasaje es destacar la inclinación de los "gamines" a la suciedad, con lo cual quiere aplicar y desarrollar teóricamente el concepto de Fourier de las "pequeñas hordas" en los niños callejeros que estudia. Sólo que en esta explicación final pasa completamente por alto la contradicción con la afirmación que hiciera al principio de los niños callejeros que nada más roban.63

Mientras que Meunier en el capítulo del "Calvario del gamín" —obviamente bajo la influencia de la tendencia victimizadora- da a entender que el "gamín" debe vivir siempre en la calle, pues es el "niño carente de amor", y que por eso la banda se convierte en un sustituto de 
la familia, de pronto, 45 páginas después, dice que el "gamín" es un "visitante de la calle" y que va de aquí para allá entre la calle, el albergue y la familia. La explicación de esta contradicción es que Meunier sólo alude a la segunda afirmación para cimentar su concepto de contrasociedad. Con estos enunciados, más bién puestos unos sobre otros, acerca de una pretendida contrasociedad, Meunier contradice también la descripción que hace más adelante del alto grado de organización de las bandas de niños callejeros, en las cuales cada miembro asume un rol bien definido.64

Otra contradicción que es frecuente encontrar en los enfoques al entorno de la sociedad consiste en que los niños callejeros, llamados "gamines", son caracterizados como "pequeños guerrilleros urbanos", "rebeldes", como "malos, insolentes y mafiosos" - lo que inequívocamente señala factores individuales en el esclarecimiento de las causas de que los niños estudiados vivan en la calle-, mientras que para la explicación teórica al final de cuenta sólo se habla de "pequeños oprimidos" de una estructura social injusta o del sadismo de los adultos como consecuencia de una sociedad autoritaria. 65

Podría continuarse en varias páginas la lista de grandes y pequeñas contradicciones de los distintos enfoques sobre la infancia callejera. Pero estas contradicciones no son la única consecuencia de la problemática provocada por la visión tan estrecha que hacen los investigadores a través de su lente teórico. Otra consecuencia consiste en que hay algunos aspectos que se dejan ocultos, sólo para no estorbar la comprensión de la teoría sustentada.

En este contexto, por ejemplo, debe criticárseles a los representantes del enfoque modernizante, que dejan completamente fuera de atención los aspectos históricos de la infancia callejera. Granados Téllez sostiene que los comienzos de ésta en Colombia se remonta a principios del siglo $\mathrm{XX}$. Aptekar, cuyo enfoque sociocultural igualmente cobra vida en relación con los procesos de modernización, considera de manera poco diferenciada que los niños callejeros colombianos la opinión pública les puso la etiqueta de "abandonados" hasta después de la guerra civil "La Violencia" —o sea después de 1948, para hacer referencia a la irresponsabilidad de los padres. Estas aseveraciones hechas únicamente en interés de la teoría, deben compararse con los resultados de investigaciones históricas, que ubican los principios de la infancia callejera más atrás, en la época colonial. También entonces se hablaba ya del "acto criminal" del abandono de los hijos por sus madres. Pero los autores que se han mencionado no se involucran en estos aspectos, para poder seguir aferrados a su teoría. 66 
Por lo demás, a todos los investigadores que destacan el maltrato de los niños callejeros como único factor, debe objetárseles que niños maltratados hay también en otros paises "altamente desarrollados", como por ejemplo en Europa, sin que éstos vayan a parar inmediatamente a la calle. También el autoritarismo es un fenómeno muy difundido en algunas sociedades "altamente desarrolladas", como por ejemplo en la sociedad japonesa, sin que por eso haya grandes cantidades de niños viviendo en las calles. Igualmente debe decírseles a los teóricos de la "miseria", que la pobreza material no equivale a desarmonía, maltrato, violencia, alcoholismo, deserción de los esposos, etc. También en circunstancias de pobreza se encuentran familias que viven en armonía, intactas. Pero estos aspectos quedan completamente fuera de consideración en una concepción teórica estrecha.

A Ballesteros Rotter se le puede reprochar que ha derivado su explicación de la psicopatología de los niños callejeros de una perspectiva muy unilateral. Pues sus afirmaciones sobre los niños de la calle están hechas en una completa separación no sólo de su contexto histórico, sino sobre todo de su contexto social, económico y cultural. Una observación tan aislada de la existencia humana no puede producir más que conclusiones erradas sobre la misma.67

También a Lewis Aptekar se le debe reprochar su falta de diferenciación en el contexto siguiente. En el curso de su teoría del conflicto cultural de las familias patrifocales y matrifocales, él se da a la tarea de demostrar que el conocimiento general sobre los niños callejeros está plagado de mitos y afirmaciones del campo de validez de su estudio: equipara los datos recogidos en Cali, con los recogidos en la capital Bogotá, que es tres veces más grande, y no toma en consideración que las realidades de los niños callejeros son diferentes, en virtud de la diferencia de tamaños, de historia y de características de estas ciudades. El colega americano de Aptekar, Felsman, había abordado ya esto haciendo énfasis en determinadas partes.68 Por eso es de extrañar con que naturalidad trata Aptekar de sostener lo contrario de dichas tesis, como la de los robos y el consumo de drogas de los niños callejeros en general - y precisamente no limitado al caso de la ciudad de Cali.

Finalmente debe abordarse el problema de que muchas de las teorías interesadas en explicar la infancia callejera, no son más que variaciones o derivaciones de afirmaciones de otras teorías más generales. Para el caso, la tesis de la urbanización del enfoque modernizante proviene de conceptos más generales de la migración del campo a la ciudad. También la tesis del vecindario delincuente tiene su origen en teorías de criminalidad, que destacan la influencia de idolos negativos. A esto se agrega en 
varios casos, la grave problemática de que las teorías que se están aplicando a los niños callejeros latinoamericanos, han nacido originalmente en otros círculos culturales muy distintos, como por ejemplo el norteamericano, lo cual se demuestra más enfáticamente en el enfoque psicopatológico.69

El problema de la aplicación de teorías preconcebidas consiste en una simplificación y parcialización de la compleja realidad humana. Aún cuando por determinadas circunstancias - como por ejemplo por escasez de los medios de investigación, etc.- es difícil eludir una forma de proceder así, no es de ninguna manera comprensible el por qué son muy pocos los investigadores que han advertido la limitación de su teoría, como lo hizo J. Kirk Felsman, quien al utilizar su enfoque teórico habla muy claramente de una apreciación parcial de la infancia callejera.70 De esta forma ha prevenido desde el principio una posible confusión, que sí se produce en la forma irreflexiva e indiscriminada de argumentación de otros investigadores.

\subsection{El problema metodológico de la accesibilidad a la realidad de los niños callejeros}

A continuación se pretende exponer cuan difícil es emplear en la investigación social con los niños de la calle métodos coherentes para tener una base sólida para el levantamiento de datos válidos, es decir, de datos no contradictorios y no distorsionados. Finalmente, debe dejarse constancia de la extrema dificultad del acceso metódico al objeto de la investigación. Al mismo tiempo debe aclararse que muchos de los investigadores no tienen la suficiente conciencia de la problemática metódica lo que debe discutirse a través de ejemplos concretos de la utilización del método. El objetivo de esta crítica al método es, por consiguiente, hacer un aporte al esclarecimiento, a un "desenmarañamiento" de la discusión tan controversial y contradictoria que se ha hecho sobre la infancia callejera.

Primeramente debe hacerse referencia al hecho de que las personas estudiadas son niños y no adultos. Esto es por una parte problemático, en el sentido que el conocimiento sobre el mundo de los niños es muy precario, debido a un déficit de investigación.71 Por otra parte, en cualquier manual metódico puede leerse que los niños son mucho más difícilmente accesibles para la investigación social que los adultos.72 Esto se basa en que la capacidad intelectual y verbal, como también el pensamiento abstracto y lógico, no están acentuados en los niños como en los adultos. Aun debe hablarse incluso de una singularidad de los procesos de observación y pensamiento infantiles, que resultan relativamente extraños frente al investigador social. Estas diferencias del mundo intelec- 
tual de las personas investigadas con el del investigador, le imponen determinadas limitaciones desde el principio al levantamiento de datos, y por ende, al proceso de investigación. Para mantener estas barreras al nivel más bajo posible, no se recomienda en la investigación social con niños el uso de los métodos cuantitativos convencionales, sino, por el contrario, se recomienda el uso de métodos cualitativos afinados, principalmente la observación participante. Pero aun así, el investigador social no está inmune de errar en la interpretación de lo que dicen o hacen los niños investigados.

En el caso especial de los niños callejeros latinoamericanos, a las dificultades técricas de investigación, se adhiere la problemática de que jurídicamente este fenómeno no debería existir. Según la ley está prohibido que los niños, como "menores", duerman y vivan independientemente en la calle, y a los que lo hacen, los considera como "menores vagos". Para estos "menores vagos" está previsto en forma oficial el reclutamiento en centros estatales de atención. Pero en forma "no oficial" existe en muchos países latinoamericanos, por diversas razones históricas y socioculturales, una tolerancia frente a los niños callejeros, que les permite su existencia. No obstante, casi siempre están conscientes de la supuesta "prohibición" de su vida en las calles, puesto que en ellas aprenden a protegerse de los "defensores de la ley". Finalmente, los niños callejeros desarrollan tendencias para justificar en las más diversas formas su existencia en la calle, diseñan estratégias que tienen como objetivo mantener su libertad en la calle. Estas estratégias terminan en un encubrimiento consciente de las verdaderas razones por las que viven así, en desinformación. En algunos países latinoamericanos han desarrollado verdaderas "técnicas" para ocultar la verdad sobre su identidad o su procedencia familiar.73 Esta hábil manipulación de la verdad (contar cuentos) junto con técnicas de supervivencia aplicadas por los niños callejeros, como por ejemplo mendigar, son lo que diariamente llevan a la práctica. A la par de esta "ilegitimidad" de la existencia y vida propia de los niños callejeros - en cuyo suelo parece desvanecerse con frecuencia la línea entre verdad y mentira, realidad y fantasía - al investigador social se le presentan otros obstáculos estructurales en el camino de un levantamiento de datos que no adolezca de contradicciones.

Este componente del que se ha dejado constancia de la "ilegitimidad" de la vida y la conducta de los niños callejeros, se acerca a una categoría que en la sociología es tratada como "conducta desviante" - esto se vuelve más claro en relación con los robos que se han mencionado varias veces. Aun cuando esta categoría supuestamente no puede trasladarse a la realidad latinoamericana de los niños callejeros - por la tolerancia general frente a los mismos que se ha mencionado-, parece acertado se- 
guir la recomendación en cuanto a la elección de un método que permita comprender lo más fácilmente posible un comportamiento tal. Nos referimos en este sentido a la observación participante. Esta se destaca por dos razones decisivas y debe calificarse por eso simplemente como el método cardinal en la investigación social con los niños callejeros.

Si bien la observación participante es, en las circunstancias expresadas, el instrumento de levantamiento de datos más adecuado, también debe decirse que ella no es suficiente para comprender a los niños callejeros. Depende mucho de la forma que utiliza el investigador para entrar en contacto con las personas estudiadas; nos referimos al rol específico que tiene el observador en el medio de los niños callejeros, es decir, que debe existir un mínimo de confianza mutua entre el investigador y las personas estudiadas. Sólo así pueden superarse las barreras de una primera desconfianza, con la que los niños de la calle reciben normalmente a las personas que no vienen de su mundo. Esta separación de mundos entre el investigador de campo y los niños callejeros se manifiesta de muchas formas - social, cultural, económica y desde el punto de vista del lenguaje-, lo cual es motivado, en último término, por la pertenencia a distintos estratos en la estructura social.

Por lo demás, debe analizarse la categoría "calle". Un investigador social consecuente lleva a cabo la observación participante, o sea, su investigación, en la calle. Pero precisamente allí debe contar el investigador con dificultades difíciles de superar. Por otro lado, las calles en las grandes ciudades latinoamericanas son reconocidas como peligrosas, esto quiere decir que los índices de robos y otros delitos perpetrados en la calle es alto. Además, no es raro que el mundo de los niños callejeros se relacione con el mundo de la criminalidad. Bajo este aspecto, la investigación se plantea como una empresa obviamente peligrosa.

Por otra parte, la calle produce en general formas de vida inestables. Esto tiene que ver, entre otras cosas, con la forma de actuar que ya hemos mencionado por parte de las autoridades, a través de redadas 0 "acciones de limpieza" que buscan dejar libres las calles de la población que vive en ellas o por lo menos desalojarla. Los niños de la calle afectados por esto, han sido descritos muchas veces como "emigrantes permanentes", que no viven ininterrumpidamente en la calle, sino que más bien van de un lado a otro entre la calle y los centros de atención, pasando por su casa $u$ otros alojamientos privados.74 $\mathrm{Al}$ investigador de campo que hace observación participante, se le plantea el problema de cómo "capturar" a un emigrante permanente así. Aún cuando el investigador lo logre abordar con espontaneidad o delicadeza en la investigación, debe resignarse a poder observar o investigar a los niños callejeros en espacios y lapsos limitados. 
En el fondo de esta discusión metodológica debe echarse una mirada a la investigación social que se ha hecho hasta ahora con niños callejeros. En especial debe hacerse una crítica a aquéllos proyectos de investigación que tratan de investigar en primer término la realidad de los niños callejeros con métodos cuantitativos. Aquí debe mencionarse, entre otros, a Granados Téllez que les pone a los niños de la calle un cuestionario estructurado con no menos de 62 preguntas, que además tienen subpreguntas. La validez de los datos que él obtuvo alguna vez deben ponerse en tela de duda. Por el contrario, la capacidad enunciativa de dichos datos presentados en estadísticas debe limitarse como muy baja. Se debe plantear, por ejemplo, la pregunta de en que medida puede aportar la afirmación global "me golpearon" para el esclarecimiento de los motivos por los cuales el niño abandonó el hogar.75 ¿Que persona no ha sido golpeada en su infancia alguna vez por sus padres, sin que haya escapado de su casa?

Qué tipo de confusiones y datos contradictorios puede ocasionar la implementación de métodos cuantitativos, se desprende también de la investigación de Aptekar. Para evaluar el estado emocional de los niños callejeros recurre primero al Test de Configuración Bendel y finalmente al Test "Human Figure Drawings". Mientras que los resultados del primer test sitúan más o menos a una cuarta parte de los niños callejeros en un rango patológico y al resto fuera de este ámbito, los resultados del segundo test arrojan exactamente el resultado contrario. Aptekar trata de justificar esto último como un artefacto de la investigación, aduciendo varios motivos. $76 \mathrm{Sin}$ embargo, esto no puede engañar acerca de lo problemático y, en parte, inadecuado que es el uso de métodos cuantitativos en la investigación de los niños callejeros.

A otros investigadores se les puede achacar la falta de contacto auténtico con las personas investigadas, lo cual tiene que ver con su renuencia a investigar en la calle. Esto llama especialmente la atención en investigadores nativos, para los cuales juega un papel importante el temor de establecer contacto con una parte de la población que es discriminada en el contexto nacional. En este sentido, es necesario contradecir a Bello Díaz, quien para la investigación de niños callejeros recomienda investigadores nativos, es decir, latinoamericanos. 77

En este contexto debe analizarse el proceder, al que ya se ha hecho referencia varias veces, de no estudiar a los niños callejeros en la calle, sino principalmente en las instituciones. Empero, hay que tener en cuenta que con frecuencia los niños se encuentran en esas instituciones contra su voluntad. Lo anterior se pone más claramente de manifiesto en Ballesteros Rotter, quien estableció en los niños callejeros que estudió un 
total de 440 ingresos involuntarios a la institución, frente a los cuales había únicamente 177 voluntarios. Además, el "malestar" de estos niños durante su estancia en las instituciones se demuestra por su rápida fuga. $\mathrm{Ni}$ aún Ballesteros Rotter puede evitar reconocerlo.78 Entonces, debe reconocerse que una situación de investigación de este tipo es artificial e intolerable para las personas estudiadas. Desde este punto de vista, debe plantearse la interrogante acerca de la medida en que pueden considerarse como válidos los datos que Ballesteros Rotter obtiene en el marco de los sintomas enumerados en el enfoque psicopatológico, que deben servir para la comprensión y explicación de la infancia callejera. ¿Que persona "normal" no se inclinaría a la "insatisfacción" o a la "tolerancia frustración limitada", si se le arrancara de su medio acostumbrado y se le encerrara contra su voluntad?

Más bien debe atribuirseles una cierta ingenuidad a estos investigadores, que piensan que pueden investigar la realidad de los niños de la calle sólo en las instituciones, es decir, sacar datos únicamente de las declaraciones de niños de la calle que están internados, sin emprender nunca un control o evaluación de dichos datos en el lugar, en el ambiente más natural de los niños callejeros - la calle. Se debe calificar de más adecuado el proceder de aquéllos investigadores que hacen por lo menos una parte de sus investigaciones en la calle. 79 Debe destacarse la investigación de Meunier, pues la lleva a cabo principal y directamente en la calle. 80

Hay que preguntarse que clase de niños de la calle estudian los investigadores. Pues no es raro encontrar individuos que puedan catalogarse de manera muy distinta dentro de la misma categoría. Ballesteros Rotter, para el caso, estudia a estas personas por igual, como niños callejeros, a algunos que apenas han estado de uno a dos meses en la institución psiquiátrica, mientras que otros ya llevan allí de 45 a 46 ó de 61 a 62 meses.81 En el caso de Aptekar, debe plantearse una interrogante similar, de como puede equiparar a esos niños que actualmente viven en la calle con otros que desde hace años se encuentran exitosamente en un proyecto y desde hace tiempo no tienen nada que ver con la calle.82 Se debe observar críticamente la pretención de algunos investigadores de querer hacer afirmaciones en general sobre los niños callejeros, cuando los niños que han investigado son casi siempre sólo los que frecuentan, por ejemplo, un proyecto determinado (Bosconia), como lo hace para el caso Aptekar, quien incluso hace de esto un componente de la definición misma del niño callejero. 83 iNo debiera hablarse en esos casos mejor en forma más diferenciada y decir únicamente "niños callejeros del proyecto"? Qué sucede con todos los niños callejeros que talvez concientemente evitan visitar esos proyectos? No son éstos, entonces, niños callejeros? ¿No 
era inevitablemente que Aptekar llegara a resultados positivos de su Test, cuando en su investigación no fueron tomados en cuenta todos aquéllos niños que estaban separados de este proyecto por violación de las normas - talvez por robo-y para los cuales seguramente no podría hacerse una evaluación tan favorecida como la que él logró establecer?

Estos aspectos mencionados al final tocan la problemática general de la representatividad. Los resultados de las investigaciones existentes se refieren casi siempre a un número reducido de personas estudiadas. Los datos de las pocas investigaciones que pretenden ser más amplias --esto es que abarcan 100 individuos - deben tomarse con escepticismo por la forma primariamente cuantitativa en que se realizan - como ya se expuso antes. 84 Se debe partir en general de que, debido al difícil acceso al objeto de estudio "infancia callejera", la posibilidad de alcanzar satisfactoriamente el criterio de la representatividad será siempre limitada. Pero para no desatender por completo un requisito como éste, y al mismo tiempo no dejar completamente de lado el tan necesario componente cualitativo de investigación, un número de 50 a 60 personas estudiadas parece ser el más adecuado. Sin embargo, en algunos estudios no se alcanza este mínimo. Para el caso, Gutierrez apoya sus afirmaciones sobre los niños callejeros, expuestas en cientos de páginas, solamente en un número de 20 personas estudiadas.85 Debería estar claro que en un caso así parece problemático sacar conclusiones para la totalidad de niños callejeros. Puede ser que Gutiérrez no haya pretendido esto de manera intencional, pero debe calificarse expresamente de problemático el hecho que después, muchos investigadores simplemente adoptaron la tipología establecida por Gutiérrez de "gamines" y "chupagruesos" y la tomaron como punto de partida de sus investigaciones sin haber estimado el limitado campo de validez de las afirmaciones de Gutiérrez. 86

\section{Panorama}

En consideración a la crítica expuesta, debe lograrse un punto de partida para un tratamiento realista y adecuado del tema de investigación de los niños de la calle. Sobre esto se debe estar claro que las investigaciones y teorías que existen hasta hoy adolecen de déficits, de manera que es necesario continuar con una investigación intensiva.

La atención debe centrarse en dos puntos esenciales. Por un lado, el conocimiento incompleto que hasta hoy se tiene sobre el lugar de vida, la "calle", debe ser enriquecido con datos que tengan fuerza declarativa. $¿$ Que influencias positivas y negativas puede traer la calle en el desarrollo de niños que crecen en ella, en qué medida puede fungir la calle como escuela? Estas preguntas han sido también subestimadas o generalmente 
excluidas en la Sociología Juvenil europea y norteamericana.87 Su respuesta es en el caso de Latinoamérica tanto más importante, porque aquí, en muchos países, la calle tradicionalmente ocupa un lugar muy importante, en la vida cotidiana de las personas. 88 Un segundo aspecto se ha quedado hasta ahora inexplorado: el aspecto familiar. $Y$ es precisamente éste el que puede dar datos más cercanos para el esclarecimiento de la pregunta de por qué motivos concretos los niños viven en la calle. El estudio principalmente aislado que se ha practicado hasta ahora, ya no puede aportar más que afirmaciones estereotipadas como las de familias de niños callejeros que los "maltratan" o los "educan normativamente". $\mathrm{Ni}$ aún los estudios de Gutiérrez de Pineda y otros, que investigan a las familias de los niños callejeros, están en la capacidad de proporcionar más que afirmaciones globales como las de familias pobres de los niños callejeros, sádicas, frías o desintegradas. 89 Tampoco los Padres Nicoló y García Durán, que tantos años estuvieron en la práctica y al mismo tiempo como investigadores, no pueden hablar más que de "imagen paterna y materna traumatizante", de una madre como "anécdota transitoria", de una "madre violada", de "algún padre", de un "hogar muerto", etc. 90 Para el esclarecimiento más exacto de éstos, como también de otros tantos aspectos, será indispensable preparar estudios comparativos así como estudios longitudinales, los cuales, pese a ser tan difícil su ejecución, tengan la capacidad de proporcionar la respuesta correcta a las tantas preguntas sobre la infancia callejera. Esta es la razón por la cual también son exigidos frecuentemente. 91

A la par de la eliminación de estos déficits en la investigación, la futura investigación debe tener como objetivo superar la oposición que siempre surge entre los enfoques al entorno del individuo y al entorno de la sociedad. En vez de eso, junto con Felsman, 92 debe exortarse a la consideración integradora de los factores al entorno del individuo y de la sociedad en la explicación teórica de la infancia callejera, que tampoco pierda de vista factores importantes como los históricos, culturales, etc. Sólo así se hará posible a largo plazo un entendimiento más profundo y, con ello, un manejo más adecuado del problema tan complejo y muchas veces malentendido de la infancia callejera latinoamericana.

\section{BIBLIOGRAFIA}

AMADO, Jorge (1986): Herren des Strandes, Reinbek: Rowohlt

ANWEILER, Oskar (1984): "Leben, Werk und Bedeutung A. S. Makarenkos", en: MAKARENKO, Anton S.: Ein pädagogisches Poem. Frankfurt am Main, Berlin, Wien: Ullstein, Págs. 5-29. 
APTEKAR, Lewis (1988a): Street children of Cali. Durham and London: Duke University Press

(1988b): "Colombian street children: their mental health and how they can be reached", en: INTERNATIONAL JOURNAL OF MENTAL HEALTH, Vol. 17, No. 3, Whithe Plains, New York, 81-104

ARFOUILLOUX; J.C. (1983): A entrevista com a criança. Rio de Janeiro: Zahar (3a. edición)

ARRUDA, Rinaldo Sérgio Vieira (1983): Pequeños bandidos. Sao Paulo: Global

BALLESTEROS ROTTER, Guillermo (1968): "Psicopatología del gamín bogotano", en: ENTREVISTA DE PSICOLOGIA, Vol. 13, No. 1/2, Bogotá, 141 - 160.

BEECHER, Jonathan; BIENVENU, Richard (1972): The utopian vision of Charles Fourier. London: Jonathan Cape

BELLO DIAZ, Gilberto (1973): "Un ensayo de autoeducación de niños marginados: "gamines", en: EDUCACION HOY, Año 3, No. 18, Bogotá, 33 - 58.

BELTRAN CORTES, Luis M. (1970): "La metamorfosis del 'chino de la calle", en: TEMAS COLOMBIANOS, Bogotá, 1 - 65.

BRUCKNER, Pascal (1984): Das Schluchzen des weißen Mannes, Berlin: Rotbuch

CAIAFA, Janice (1985): Movimento punk na cidade. Rio de Janeiro: Zahar

CLASTRES, Pierre (1988): A sociedade contra o estado. Rio de Janeiro: Francisco Alves (4a edición)

CONFERENCIA NACIONAL DOS BISPOS DO BRASIL (1987): Quem acolhe o menor, a mim acolhe. Brasilia: Campanha de fraternidade

CORDOVEZ MOURE, José María (1962): Reminiscencias de Santa Fé y Bogotá. Madrid: Aguilar (2a edición)

DELEUZE, Gilles; GUATTARI, Felix (1980): Mille Plateaux. Paris: Minuit

FELSMAN, J. Kirk (1981a): Street urchins of Cali: on risk, resiliency and adaptation in childhood. Cambridge: Harvard University (Tesis doctoral inédita)

-------(1981b): "Street urchins of Colombia", en: NATURAL HISTORY, April 1981, New York, 41 - 48.

--(1984): "Abandoned children: a reconsideration" en: CHILDREN TODAY, Vol. 13 (3), May-June 1984, Waschington D.D., 13 - 18.

(1985): "Abandoned children reconsidered: prevention, social policy and the trouble with sympathy", en: PROCEEDINGS OF THE INTERNATIONAL CONFERENCE OF PREVENTION, April - May 1985, University of Montreal, Canada, 1 - 15.

(1989): "Risk an resiliency in childhood: the lives of street children" en: DUGAN, Timothy F.; COLES, Robert (Editor): The child in our times: studies in the development of resiliency. New York: Brunner/Mazel, $56-80$. 
FERREIRA, Rosa María Fischer (1980): Meninos da rua. Sao Paulo: Centro de Estudios de Cultura Contemporánea (CEDEC)

FRIEDRICHS, Jürgen (1985): Methoden empirischer Sozialforschung. Opladen: Westdeutscher Verlag (13a edición)

GARCIA DURAN, Alejandro (1982): La porción olvidada de la niñez mexicana. México: Diana (4a edición)

GRANADOS TELLEZ, Marcos F. (1976): Gamines. Bogotá: Temis (2a edición)

GUTIERREZ, José (1967): Infancia de la miseria. Bogotá: Biblioteca de Bolsillo

-----(1972a): Gamín: un ser olvidado. México, Panamá, Bogotá, etc.: Mc Graw-Hill

(1972b): "The gamines", en SCIENCE AND PSYCHOANALYSIS, No. 21, New York, 45 - 60.

GUTIERREZ PINEDA, Virginia; PERRY DE MUÑOZ, Elvia Isabel; VILA DE PINEDA, Patricia; ECHEVERRY, Yolanda; ARIAS, Jairo (1978): El gamín. Volumen I. Bogotá: UNICEF/Instituto Colombiano de Bienestar Familiar.

KUBIE, Lawrence S. (1956): Psychoanalyse ohne Geheimnis. Hamburg: Rowohlt

MELLO FILHO, Julio de (1989): O ser e o viver. Porto Alegre: Artes Médicas

MEUNIER, Jaques (1979) : Die Straßenkinder von Bogotá. München: Trikont

MONDELL, Sid; TYLER, Forrest B. (1981): "Child psychological competence and its measuremente", en: JOURNAL OF PEDIATRIC PSYCHOLOGY, Vol. 6, No. 2, New York, 145 - 154.

MONTENEGRO DE CASTRO, Martha (1973) : Estudio de una muestra de las familias que generan el gaminismo en Bogotá. Bogotá: Universidad Nacional de Colombia (Trabajo de graduación inédito)

MUÑOZ V. Cecilia,; PACHON C., Ximena (1979): "El gamín, un emigrante permanente", en: LOS NIÑOS (Instituto Colombiano de Bienestar Familiar), No. 7, Febrero 1979, Bogotá, 24 - 30.

-(1980): Gamines: Testimonios. Bogotá: Carlos Valencia

NEME, Mijail (1966): "Los niños vagabundos de Tucumán" en: ARCHIVOS DE CRIMINOLOGIA, NEURO-PSIQUIATRIA Y DISCIPLINAS CONEXAS, Epoca 2, Vol. 14, No. 56, Quito, 529 - 542.

NICOLO, Javier de (1981): Musarañas. Bogotá: Servicio Juvenil

POLLMANN, Uwe (1986): "Zwischen Arbeit und Bandentum: Straßenkinder in Brasilien", en: SOCIOLOGUS 36/2, Berlin, 138 - 161.

RODRIGUEZ F., Jaime (1986): "El muchacho de la calle. ¿Educación vs. marginalidad o marginalidad vs. educación?", en: EDUCACION HOY. Año XVI, No. 94, Bogotá, 21-44 
ROGGENBUCK, Stefan (1993): Straßenkinder in Lateinamerika. Sozialwissenschaftliche Vergleichsstudie: Bogotá (Kolumbien), Sao Paulo (Brasilien) und Lima (Perú). Frankfurt am Main etc.: Peter Lang

STUBBE, Hannes (1988): Moleques. Mannheim (inédito).

TAÇON, Peter (1981): My child minus two. (Sin lugar). UNICEF

TYLER, Forrest B. (1984): “El comportamiento psicosocial, la competencia psicosocial individual y las redes de intercambio de recursos como ejemplos de psicología comunitaria", en: REVISTA LATINOAMERICANA DE PSICOLOGIA, Vol. 16, No. 1, Bogotá, 77 - 92

TYLER, Forrest B.; TYLER, Sandra L.; ECHEVERRY, John J. (1987): “Características psicosociales de los gamines de "Bogotá", en: CUADERNOS DE PSICOLOGIA, Universidad del Valle.

UGARTE, Oscar (1987): "Exposición sobre „Programas de asistencia al menor en el Perú «", TIPACOM: El menor en situación de abandono. Lima: Tipacom, 43 -52 .

UNICEF (1987): Nuevas alternativas de atención para el niño de y en la calle de México. Bogotá: UNICEF, Serie metodológica, Programa regional: menores en circunstancias especialmente difíciles, No. 3

VILLEGAS M., Nora Eugenia (1977): "El gamín", en: REVISTA DE SOCIOLOGIA, Vol. 9, No. 12, Medellín, 33 - 37.

ZINNECKER, Jürgen (1979): "Straßensozialisation", en: ZEITSCHRIFT FÜR PÄDAGOGIK, 25. Jahrgang, No. 5, Weinheim, 727 - 746.

\section{Notas}

1. Una discusión más amplia del asunto presentado en el siguiente artículo se encuentra en la primera parte de mi estudio "Los niños de la Calle en America Latina. Estudio Comparativo en Ciencias Sociales: Bogotá (Colombia), Sao Paulo (Brasil) y Lima (Perú)", publicado en idioma alemán en 1993. Vea Roggenbuck, 1993: 8-52. Agradezco al sociólogo salvadoreño-mejicano, Rafael Guido Béjar, por su colaboración y apoyo en la discusión de la traducción del presente texto.

2. Para variar el lenguaje, en este artículo se utiliza los términos "niño(s) de la calle", niño(s) callejeros" en el mismo sentido que corresponde a la definición aquí presentada.

3. Vea las definiciones detalladamente en Ballesteros Rotter 1968: 49 y Felsman 1981a: 11 .

4. La siguiente presentación se refiere en primer lugar a las exposiciones de Ballesteros Rotter 1968: 149 y sigs. Los psiquiatras colombianos López Pardo/López Vergara habían llegado a un descubrimiento similar de la "Psicopatología de los gamines bogotanos"; compare las referencias que hace Ballesteros Rotter 1968: 149, así como Beltrán Cortes 1970: 4 y 9. 
5. Ballesteros Rotter, 1968: 158

6. El libro apareció en 1977 en la versión original francesa, en 1978 en una versión portuguesa, y en 1979 en una traducción al alemán de Barbara Polten, Karin Hoetzer y Joscha M. Merkl; la última es la que sirve de base para esta consideración.

7. Meunier, 1979: 26, 45, 58, 104.

8. Meunier, 1979: 46.

9. Meunier, 1979: $111 \mathrm{y}$ sig.

10. Meunier, 1979: 50, 92.

11. Clastres ilustra el concepto de contrasociedad por medio de pueblos primitivos de Latinoamérica y su organización política; Clastres, 1988: 140 y sigs.

12. Deleuze/Guattari, 1980: 442y sigs. Vea también las explicaciones sobre "bandas nómadas" de Perlongher, 1987: 193y sigs, o la interpretación del movimiento Punk de Rio de Janeiro como contrasociedad, por Caiafa, 1985: 113, $122,137 y$ sig.

13. Beecher/Bienvenu, 1972: 315 y sigs.

14. Meunier, 1979: 133.

15. La siguiente discusión se apoya sobre todo en la tesis doctoral inédita de Felsman, presentada en 1981 en la Universidad de Harvard, USA.

16. Felsman, 1981a: 159.

17. En el enfoque de la competencia psicosocial individual, por "coping" se entiende un maniobrar activo; compare Tyler, 1984: 79 y sig. Para la investigación de la competencia psicosocial de los niños callejeros de Bogotá, el autor hizo una investigación propia; vea los resultados de la misma en Tyler/Tyler/Echeverry: 1987, 15 y sigs.

18. Felsman, 1981a: 157.

19. Felsman, 1981a: 166.

20. Felsman, 1989: 75 .

21. Felsman, 1984: 18.

22. Gutiérrez, 1967: 12.

23. Gutiérrez, 1972b: 50 .

24. Gutiérrez, 1972a: 47, 116, 128.

25. Gutiérrez, 1972a: 115 y sig., 118.

26. Gutiérrez, 1972a: 288, 327.

27. Gutiérrez, 1972a: 118, 162; y 1967: 19 y sigs.

28. Gutiérrez, 1967: 18 y sig., y 1972a: 136, 138, 279.

29. Granados Téllez, 1976: 62 y sig.

30. Muñoz/Pachón, 1980: 102 y sig.

31. Montenegro de Castro, 1973: 94 y sigs., Gutiérrez de Pineda y otros, 1978: 242 y sig., Muñoz Pachón, 1980: 101, y Granados Téllez, 1976: 63.

32. Algunos defensores del enfoque socioestructural dividen el proceso que se plantea en etapas bien definidas; así lo hace, por ejemplo en "Proceso de Gaminización" Nicoló 1981: 48 y sigs., en "Círculo de Marginalización de los Menores de Edad" la Conferencia Nacional dos Bispos do Brasil 1978: 15 y sig. Villegas M. desarrolla un esquema de tres fases, Villegas M. 1977: 34 y sig. Vea argumentaciones similares en Bello Díaz 1973: 43 y sigs., Ferreira 1980: 75 y sig., Arruba 1983: 51 y sigs. y Pollmann 1986: 139 y sig. 
33. Rodríguez F., 1986: 36 y sigs.

34. Nicoló, 1981: 334.

35. García Durán, 1982: 172.

36. García Durán, 1982: 170, 182 y 186.

37. Taçon, 1981b: 36 y sigs.

38. García Durán, 1982: 188.

39. García Durán, 1982: 201, 190 y sigs. y 186 y sigs.

40. Aptekar, 1988a: 28, 33.

41. Felsman, 1981a: 158.

42. Aptekar, 1988a: 118 y sig., 120, 126, 136, 141, 146 y sig.

43. Gutiérrez, 1972a: 47.

44. Aptekar, 1988a: 83.

45. Aptekar, 1988a: 112.

46. Aptekar, 1988a: 185.

47. Aptekar, 1988a: 174 .

48. Aptekar, 1988a: 182.

49. Beltrán Cortés, 1970: 8.

50. Felsman, 1985: 3 y sigs.

51. García Durán, 1982: 12

52. Gutiérrez de Pineda y otros, 1978: 253.

53. Bruckner, 1984: 73 y sigs.

54. García Durán, 1982: 11 y sigs.

55. Amado, 1986: 200 y sigs.

56. Anweiler, 1984: 12 y sig.

57. Aptekar, 1988a: 113 y sig.

58. Gutiérrez, 1972a: XIV, 128.

59. Nicoló, 1981: 298.

60. Conferencia Nacional dos Bispos do Brasil, 1987: 6

61. Meunier, 1979: 129

62. Meunier, 1979: 53 y sig. y Nicoló, 1981, 330

63. Meunier, 1979: 26 en oposición a pág. 131

64. Meunier, 1979: 47 y sigs. en oposición a pág. 92.

65. Así por ejemplo Gutiérrez 1972a: XIV en oposición a pág. 327, y Nicoló, 1981: 50 en oposición a pág. 424.

66. Granados Téllez, 1976: 1, y Aptekar, 1988a: 155 y sig. en oposición a Cordovez Moure, 1962: 919, así como a Ortega Ricaurte, 1972: 10 y sig.

67. Vea Ballesteros Rotter, 1968: 149 y sigs.

68. Felsman, 1981a: 65, 97, 102, y 1981b: 44

69. Vea Ballesteros Rotter, 1968: 159. Aquí se aplica irreflexiblemente la teorìa psicoanalítica norteamericana de Melanie Klein al problema de los niños callejeros colombianos. Algunos autores aluden, en relaciòn a los niños callejeros brasileños, a la inaplicabilidad de este procedimiento; Mello Filho, 1989: 104, y Stubbe., 1988: 25 y sig.

70. Felsman, 1981a: 10 y sig., 42. Sus afirmaciones teòricas ("invulnerabilidad") las refiere únicamente a menos de la mitad del total de niños callejeros que investigó originalmente. 
71. El tema de los niños se empezó a tratar como tema de investigaciòn hasta principios del siglo XX; Arfouilloux, 1983: 173.

72. Como en Friedrichs, 1985: 274.

73. En México se le llama a este procedimiento "técnica de Pepito", en Colombia, "chapa"; UNICEF, 1987: 27, 31, y Nicoló, 1981: 106. También en Perú se pudo constatar la existencia de esta "técnica" de los niños callejeros; Ugarte, 1987: 46.

74. Muñoz/Pachón, 1979: 24.

75. Granados Téllez, 1979: 16.

76. Aptekar, 1988a: 35.

77. Bello Díaz, 1973: 51.

78. Ballesteros Rotter, 1968: 156 y sigs.

79. Así como hizo Felsman, quien ademàs de 25 horas de trabajo/investigación en el proyecto Bosconia, dedicó 15 horas en la semana a la observaciòn participante en la calle; Felsman, 1988a: 9 y sig.

80. Meunier, 1979: 51 . El autor cuenta que tuvo que recorrer 1,000 kilòmetros en las calles de Bogotá, durante su observaciòn participante

81. Ballesteros Rotter, 1968: 151 y sig.

82. Este es el caso del niño callejero Giraldo, presentado por Aptekar, quien ya no vive en la calle desde hace más de 5 años; Aptekar, 1988a: 101

83. Aptekar, 1988b: 92.

84. Como en Granados Téllez, 1976: 75 y sig. y en Ballesteros Rotter, 1968: 150

85. Gutiérrez, 1972a: 61 y sigs. y 1972b: 57 y sigs.

86. Como Aptekar, 1988a: 54 y Meunier, 1979: 49.

87. Zinnecker, 1988a: 54 y Meunier, 1979: 49.

88. Así como en el caso de Brasil; Stubbe, 11988: 2.

89. Gutiérrez, 1972a: 327, y Gutiérrez de Pineda y otros, 1978: 242 y sig

90. Nicoló, 1981: 206, 332, García Durán, 1982: 170 y sigs.

91. Asì como por Chester M. Pierce en Gutiérrez, 1972b: 59 y en Felsman, 1984: 18.

92. Felsman, 1984: 18. 